\title{
The triangle teacher - pupil - knowledge in e-learning environment
}

\author{
Centre of Excellence "Metodi e sistemi per l'Apprendimento e la Conoscenza" \\ Research Group \\ University of Salerno
}

\begin{abstract}
Our proposal starts from the study of the epistemological statute of the didactics of the mathematics (Henry, 1991; D'Amore, 1999), which faces the phenomenon of learning fromthe point of view of fundaments, in order to give useful and specific considerations for e-learning environment. In particular we will focus on how the triangle teacher-pupil-knowledge changes when we use e-learning platforms.
\end{abstract}

Keywords: Didactical triangle, learning, author, tutor, pupil, knowledge, platforms, e-learning

\section{INTRODUCTION}

Today it is a shared opinion, for researchers of didactics, that better teaching is just necessary condition but not sufficient in order to have better learning. A motivating and interesting situation for the pupil does not imply automatically a construction of the learning. At this case we cite Moreno Armella (1999): "Teaching, as simple process of instruction, together with the hypotheses on the capabilities of the pupil of absorbing what it is "well" said, is not a conception: it is an illusion». Our opinion is that most of the attention of people proposing e-learning environment has been directed until now mainly to the content, so to the teaching process, supposing that learning occurs. We are often in front of winning and motivating "artificial" environments, many times "closed in themselves", rigidly implemented according black-box strategies (Buchberger, 1990; Drijvers, 1995), without posing the key question if the cognitive transfer occurs. For such reason our intention is to exploit the results obtained in didactics of the mathematics, avoiding to "re-invent the wheel" (Drijvers, 1995), in order to construct tools of analysis and interpretation for e-learning environment; to create such environment so that they aim to learning process taking into account the results obtained in didactics; to understand from the history of this recent discipline which critical point can exist and on which it is important to focus and to start researches for e-learning in the frame of the epistemology of the learning.

\section{THE TRIANGLE “PUPIL-TEACHER-KNOWLEDGE” IN DIDACTICS}

During last twenty years the research in didactics of mathematics has analysed in various modes and with accurate details, what it is beyond the triangle whose "vertices" are the pupil, the teacher and the knowledge (Chevallard e Joshua, 1982; Chevallard, 1985; D’Amore, 1999; D’Amore e Fandiño, 2002):

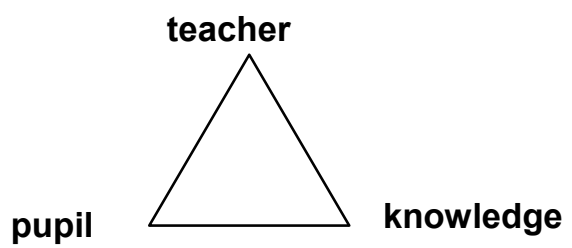

According to didactics, it represents a systemic model useful to situate and analyze the multiple relations among the three "figures" representing the "vertices" of the triangle. The complex nature of the systemic model comes from considering at the same time all the mutue relations among the vertices, including various implications of different nature.

For an accurate deepening of such topic we cite the synthesis in D'Amore e Fandiño (2002). In such analysis, the triangle has not an explicative and descriptive function of the education experience but, above all, methodological: each vertex of the system is the observer from which we look at the relations betweens the others, even if we are conscious that none of the involved figures can be considered totally separated by the others. 
Moreover the implicit effort is to render such scheme as more comprehensible as possible of the multiplicity of variables involved on the educational experience intended as problematic experience.

In such systemic model we can distinguish at least three categories of incident bodies:

- elements (that are the "vertices" or poles)

- relations among the elements (that are the "sides")

- processes that identify the functional modalities of the system.

On the triangle the noosphere (Chevallard, 1992) insists, that is the external world, the society, the collection of the people which prepare the contents and the teaching methods, with their waits, their pressures, their a priori choices.

Our intention is to revise such systemic model in the light of the present and great introduction of the ICT in teaching/learning environments, in particular when e-learning platforms are used.

\section{HOW THE DIDACTICAL TRIANGLE CHANGES WHEN E-LEARNING PLATFORMS ARE USED}

In the following we will consider distance e-learning environment, but in the future we plan to study the same topic in blended learning environment. The different management of the platform impacts in different ways on the vertices and on the relations among them.

The didactical triangle becomes w.r.t. such reference framework a more complex structure with new vertices and different relations. It is our opinion that the vertices involved in the learning process under such environment are four: the author, the tutor, the pupil, the knowledge. Not in all the platforms the figure of the tutor is foreseen but we consider essential this presence in order to have an effective learning. We do the hypothesis of the following structure where the introduction of the ICT has a total influence, with different levels of deepness, on the four vertices and on different arised relations and implications:

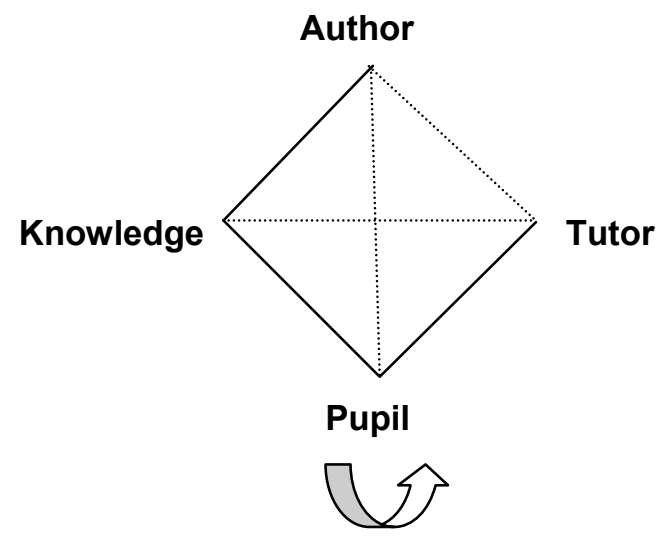

In our opinion such scheme concerns the complex system of the relations arisen among the figures interacting in the learning process when we use a distance learning platform, defining at the same time the specificity and the problematic aspects. Of course, we point out the influence of the noosphere.

\subsection{The "vertices"}

- The author. In traditional teaching the teacher is author, tutor, evaluator of his/her course. In an e-learning environment it is possible to focus on two specific figures: the author and the tutor. The first is not yet a single figure, but with this name we mean a group of persons with different professional skills: the instructional designer/manager, the graphical expert, the ICT expert, the didactical (general and disciplinary) expert, the pedagogical expert, the sociologist, the knowledge domain expert, the communication expert... The richness of the involved figures in such pole allow to create a variegated scenario of pedagogical waits concerning knowledge, of professional or ideological beliefs, of implicit philosophies (Porlán et al., 1996) that supplies with an enrichment of the platform. We consider that the comparison, the discussion, the thoughts that can occur among the different experts above, having diverse experiences, allow to take decisions about the content (didactical transposition) ${ }^{1}$

${ }^{1}$ The didactic transposition is intended as the work of transforming the knowledge in object to be taught w.r.t. to the place, the audience and the didactic finalities to be reached. Thus the teacher has to do a transposition from the 
(Chevallard, 1985, 1994; Cornu e Vergnioux, 1992) to be insert in the platform and about the methodologies through which a certain content is introduced (didactic engineering ${ }^{2}$ ) (Artigue, 1989, 1992), arrivino in such way to the construction of a reach and deep product.

- The knowledge. We mean as knowledge the academic, official one, the result of the research, which represents the stakes of the educational system and that presents specific structural, methodological, historical and cultural characteristics. It is interesting to consider that the ICT tools allow new ways of presentation of knowledge (dynamical and interactive instruments, virtual manipulations, simulations, animations...) and new knowledge. Such knowledge will not be exclusively disciplinary anymore but they will be incremented with ICT foreign languages competencies. From such point of view the necessity of information alphabetization represents a strong theme of discussion in international scene, as attested for example by the project ILSS (International Life Skills Survey) that foresees to measure not only competencies like literacy, numeracy and problem solving, but also competencies of information alphabetization (Gal, 1999).

- The pupil. Nowadays the addresses of the training, besides the young people who attend full time schools and universities, will be workers, professionals, adults involved in lifelong education (Butera, 2002). Even in e-learning environment, according our opinion, there is the necessity to make reference to cultural and cognitive projects that are personal as much as possible so that they are not filtered by the relationship of scholarisation which is an obstacle to the liberty of the personal experiences of a learner (D'Amore, 1999). The major risk is to create structure where the leaner cannot construct his knowledge by himself. Thus it is necessary to avoid that the platform is structured in such a way that the author is the only responsible of the choice of the significant knowledge for the pupil, fostering so the student to give up to to farsi carico personale of his choice according the preference, the interest, the motivation. Moreover it would be opportune to study a learning environment in order to foster the actual attention to the "fundamental stones of the foundation" of the knowledge: the actual competencies (Borkowski e Muthukrishna, 1994; Cornoldi et al., 1995), the waits (Elliott e Dweck, 1988), the beliefs (Nicholls et al., 1990; Pajares e Miller, 1994) and the personal cognitive style of the learner (De La Garanderie, 1980; Gardner, 1993; Sternberg, 1996).

- The tutor. The tutor represents the privileged figure of our structure having actual contact with the learners. When we refer to the tutor, we mean not a single people, but often we mean a group of people who take care of a certain number of students, ensuring at the same time variety of thoughts, proposals, besides the deepness of the relationships. The role of the tutor impact different areas: management/organisation, social and didactical (Cosetti e Pallavisini, 2002).

\subsection{The "relations"}

We consider the following relations among vertices:

- author-knowledge, characterised by the verb "trasporre", where the main activity is the first part of the didactical transposition from the knowledge to the knowledge to be taught that have to be realised trying to avoid the possibilities of misconceptions.

In particular in the relation author-knowledge it is fundamental the phase of projecting a-didactical situations (Brousseau, 1986) through which the learner constructs personally his knowledge; the proposals have not to be explicitly didactical, in the sense that the learner has to be involved in an activity but he has not to explicitly know which are the cognitive finalities to reach. Proposing a-didactical situations, the author realize the devolution phase that represents the action of the author towards the pupil so that this latter is encouraged to involve himself through the methodology integrated in the platform. The motivation at the basis of the implication is conditioned by the choice of the contents, how they are structured, the adopted methodology to present them, thus the phase of projecting is fundamental and it is bound to the type of Learning Object supported by the platform. The phase of institutionalisation of the knowledge is also fundamental (Brousseau, 1994), that represents the final step of the adidactical situation, needed to transform the "personal knowledge" in "institutional knowledge".

knowledge (arisen from the research) to the knowledge to be teached (selected by the institutions) to the taught knowledge (chosen by the teacher as specific object of his didactic work).

${ }^{2}$ The studies on didactic engineering concern in particular the elaboration of didactic sequences, the creation of tools and didactic material organised coherently to the reaching of specific learning objectives. Actually with such word we refer to a research methodology of qualitative type (Sarrazy, 1995; Farfán Márquez, 1997). 
- author-pupil there is no direct relation between these two vertices that are mediated by the knowledge, pointing out so the relations author-knowledge and knowledge-pupil, even if the activity of the author is indirectly finalised to the pupil. Thus we have chosen to sketch such relation.

- knowledge-pupil it is expressed by the verb "to learn" but the use of technologies has had a great impact on the accesses to such knowledge. The last phase of the didactical transposition from knowledge to be taught to taught knowledge, so to actually learned knowledge has realized by the pupil, with the possibly constant guide of the tutor. Without the help of such figure, the pupil should be able to have great critical capabilities needed for an autonomous learning, to know which choices are adequate, to be able to self-evaluate, to have great equilibrium in order to take into account meta-cognitive competencies, to have decisional power, to be able to evaluate different situations, to be well responsible (due to the absence of attendance and time constraints)...; competencies that can be attenuated by the mediation of the tutor and by tools available in the platform, such automatic tests or intelligent agents which take part on the learning path.

The phase that characterises such relation is the implication that is the action of the pupil on himself once accepted the devolution, taking personal care of his own knowledge (phase that can occur if the author has foreseen adidactical situations). The "knowledge" is so constructed by the pupil and its validity is transferred by the acceptance of the community interested to the problem by the phases of validation ${ }^{3}$ and socialisation and determined above all by the needed phase of institutionalisation of the knowledge foreseen by the author.

- author-tutor is characterised by the verb "to collaborate". In fact we wish that there will be collaboration between the author and the tutor otherwise some difficulties can occur such as not sharing of the choices, different conceptions, difficulties for the tutor to understand the methodological choices that are at the basis of the platform. All such things can imply great risks on the relation tutor-pupil, creating misunderstandings in the management and interpretation of the contents of the platform. Such relation is less evident w.r.t. the others, this is why we have chosen to sketch it.

- tutor-pupil is represented by the verbs "to facilitate - to advice - to guide". In fact the tutor should allow an harmonisation of the different phases of the learning process, a "help" in the didactical environment, both affective and emotional, a sort of "orchestra director" which allows the management of the times, a reference point for the choices of the pupil (w.r.t. to the contents or the personalised learning styles), an investigator and possibly a "solver" of the possible misconceptions, or false beliefs that will be evident by the doubts of the pupils... Generally in the platforms such figure is not appraising, so the "classical" a-symmetric situation between teacher and pupil is not so stressed, in particular when an automatic evaluation is foreseen or even if the final phase of evaluation is not foreseen or if such phase is managed by a person different from the tutor. In all such cases the didactic contract ${ }^{4}$ is remarkable modified because it is no more communicated by the evaluation phase.

- tutor-knowledge is expressed by the verb "to manage". The tutor acts as manager of the courses: he can define a programme, homeworks, deadlines and priorities, he can insert the material he judges suitable w.r.t. the course he is creating/managing. In such relation the didactic engineering is included, agreed as a modality of elaboration of sequences, tools and didactic material finalised to the learning of specific contents and as methodology finalised to the organisation, transmission and acquisition of specific competencies that are object of the teaching/learning process. According to our opinion such relation is filtered by the relation tutor-pupil, since the choices of the tutor about the knowledge are always addressed to the pupil, this is why we have chosen to sketch it in the picture.

\footnotetext{
${ }^{3}$ The validation is the process adopted in order to reach the belief that a certain obtained result (or a constructed idea) actually corresponds to the requirements explicitly implied; this can occur when a pupil poses himself in an explicitly communication situation, addressing his attention to the transformation of his own personal knowledge in a communication product, validating so his construction.

${ }^{4}$ The idea of didactic contract is the following: «In a teaching situation, prepared and realised by a teacher, the pupil has generally the to solve a (mathematical) problem that has presented to him/her, but the access to such task has made trough an interpretation of the posed questions, of the given information, of the imposed constraints that are constant in the way of teaching of the teacher. Such (specific) behaviour of the teacher expected from the pupil and the ) behaviour of the pupil expected from the teacher constitute the didactic contract» (Brousseau, 1980). The expectations that characterize the didactic contract are often due to implicit agreement depending on the conception of the school, of the mathematics ...
} 
- pupil-pupil can be represented by the verb "to socialise". Such relation assumes a greater emphasis in elearning environment. The reason of the greater interest we give it is due to the fact that in the classical didactic such relation is in some way "natural" due to the physical contact among teachers and pupils; instead the elearning environment foresee a privileged contact with the computer, addressing principally an individual learning process, that results a solitary construction, while it is the product of a real and complex interaction with the members of the micro-society the pupil is part of. Thus the cognitive activity is a behaviour that is realised through the interaction among people: it is an inter-subjective process that is socially organised and it is specific w.r.t. a context (Cole, 1996): "the learning process of an individual is fostered by the interaction of a group " (Butera, 2002). So the new technologies have to support and foster the collaborative learning through communication systems, shared synchronous, systems supporting group processes.

The need of the "social" factor has brought today to the born on the net of the learning communities and of the practice communities (Ligorio, 1996); in fact it is important that the pupil identifies himself in a community, even if in a virtual one.

\section{REFERENCES}

[1] Artigue M. (1989). Epistemologie et didactique. IREM. Paris VII.

[2] Artigue M. (1992). Didactic engineering. In: Douady R. e Mercier A. (eds.). Research in didactique of mathematics: Selected papers (Special issue). Recherches en didactique des mathématiques. 12, 41-65.

[3] Borkowski J. G., Muthukrishna N. (1994). Lo sviluppo nel bambino: un modello utile per introdurre l'insegnamento metacognitivo in classe. Insegnare all'handicappato. 8, 3.

[4] Brousseau G. (1980). Les échecs électifs dans l'enseignement des mathématiques à l'école élémentaire. Revue de laryngologie, otologie, rhinologie. 101, 3-4, 107-131.

[5] Brousseau G. (1986). Fondements et méthodes de la didactique des mathématiques. Recherches en didactique des mathématiques. 7, 2, 33-115.

[6] Brousseau G. (1994). Perspectives pour la didactique des mathématiques. In : Artigue M., Gras R., Laborde C., Tavignot P. (eds.) (1994). Vingt ans de didactique des mathématiques en France. Hommage à Guy Brousseau et Gérard Vergnaud. Grenoble: La Pensée Sauvage. 51-66.

[7] Buchberger B. (1990). Should students learn integration rules? Sigsam Bulletin. 24, 1, 10-17.

[8] Butera F. (2002). Lo scenario sociologico: l'eLearning per una "knowledge organisation". In Proc. of International Conference eLearning: una sfida per l'Università.

[9] Chevallard Y. (1985). La transposition didactique. Du savoir savant au savoir enseigné. Grenoble : La Pensée Sauvage.

[10] Chevallard Y. (1992). Concepts fondamentaux de la didactique: perspectives apportées par une approche antropologique. Recherches en didactique des mathématiques. 12, 1, 73-112.

[11] Chevallard Y. (1994). Les processus de transposition didactique et leur théorisation. In: Arsac G., Chevallard Y., Martinand J. L., Tiberghien A. (eds.) (1994). 135-180.

[12] Chevallard Y., Joshua M.A. (1982). Un exemple d'analyse de la transposition didactique: la notion de distance. Recherches en didactique des mathématiques. 3, 1, 159-239.

[13] Cole M. (1996). Cultural psychology. Belknap, Cambridge e Londra.

[14] Cornoldi C., Caponi B., Falco G., Focchiato A., Lucangeli D., Todeschini M. (1995). Matematica e metacognizione. Trento: Centro Studi Erickson.

[15] Cornu L., Vergnioux A. (1992). La didactique en questions. Paris: Hachette.

[16] Cosetti A., Pallavisini F. (2002). "Tutor, dove sei?". Aspetti teorici e pratici del tutoring online. In Proc. of International Conference eLearning: una sfida per l'Università.

[17] D’Amore B. (1999). Elementi di Didattica della Matematica. Bologna: Pitagora.

[18] D'Amore B., Fandiño M. (2002). Un acercamiento analitico al "triangolo de la didáctica". Educación Matemática. In corso di stampa.

[19] De La Garanderie A. (1980). Les profils pédagogiques. Paris: Centurion.

[20] Drijvers p. (1995), White-Box/Black-Box revisited. The International DERIVE Journal, n. 1, 3-14.

[21] Elliott E. S., Dweck C. S. (1988). Goals: an approach to motivation and achievement. Journal of Personality and Social psychology. 54, 1.

[22] Farfán Márquez R. M. (1997). Ingeniería Didáctica. Mexico D.F.: Grupo Editorial Iberoamérica.

[23] Gal I. (1999). Large scale assessment of functional mathematical skills: The International Life Skills Survey, en

[24] Gardner H. (1993). Educare al comprendere. Stereotipi infantili e apprendimento scolastico. Milano: Feltrinelli.

[25] Henry M. (1991). Didactique des Mathématiques. IREM de Besançon. Besançon.

[26] Ligorio M.B. (1996). Le Comunità di Apprendimento: tutti apprendisti, tutti insegnanti, tutti scienziati. In Trentin

G. Didattica in rete. Internet, telematica e cooperazione educativa. Garamond. 
[27] Moreno Armella L. (1999). Epistemologia ed Educazione matematica. La matematica e la sua didattica. 1, 4359.Martini B. (2000). Le didattiche disciplinari. Bologna: Pitagora.

[28] Nicholls J., Cobb P., Wood T., Yackel E., Patashnick M. (1990). Assessing student's theories of success in mathematics: individual and classroom differences. Journal of Research in Mathematics Education. 21, 2.

[29] Pajares F., Miller M. D. (1994). Role of Self-Efficacy and Self-Concept Beliefs in Mathematical Problem Solving: A Path Analysis. Journal of Educational Psychology. 86, 193-203.

[30] Porlán R. e altri (1996). Conocimiento profesional deseable y profesores innovadores. Investiogación en la Escuela. 29, 23-37.

[31] Sarrazy B. (1995). Le contrat didactique. Revue française de pédagogie. 112, 85-118. [L'articolo è pubblicato in italiano su: La matematica e la sua didattica. (1998). 2, 132-175].

[32] Sternberg R. (1996). Stili di pensiero. In: Vinello R., Cornoldi C. (eds.) (1996). Metacognizione, disturbi di apprendimento e handicap. Hillsdale: L.E.A. 